\title{
A note regarding conditioned attention theory
}

\author{
GARY A. SZAKMARY \\ Princeton University, Princeton, New Jersey 08540
}

\begin{abstract}
Two experiments employing rats in an Estes-Skinner CER procedure are reported. In Experiment 1, subjects were preexposed to two stimuli in one of two temporal relationships. $S_{1}$ either preceded $S_{2}$ or was explicitly unpaired with $S_{2}$. When subsequently paired with shock, $S_{1}$ produced greater response suppression in the group for which $\mathrm{S}_{1}$ and $\mathrm{S}_{2}$ had been paired. In Experiment 2, it was demonstrated that the pairing of $S_{1}$ and $S_{2}$ did not enhance subsequent conditioning of $S_{1}$; rather, the "unpairing" of those stimuli appeared to retard conditioning of $S_{1}$. These findings are consistent with each of two recent accounts of response decrement effects (Lubow, Alek, \& Arzy, 1975; Wagner, in press), but also admit to other interpretations.
\end{abstract}

Lubow and his colleagues (Lubow, Alek, \& Arzy, 1975; Lubow, Schnur, \& Rifkin, 1976b) have recently proposed a "conditioned attention" theory of latent inhibition and related phenomena. The theory asserts (1) that attention is governed by the laws of Pavlovian conditioning, (2) that an attentional response is elicited by the first presentation of an otherwise neutral stimulus, (3) that this response is maintained when the stimulus is followed by any environmental change, and (4) that the response decreases when the stimulus is not followed by a change in the environment. The repeated, isolated presentation of a novel stimulus is thus said to establish "conditioned inattention" to that stimulus. This state, it is argued, mediates the response decrement effects observed in latent inhibition, habituation, and the stimulus familiarization effect (cf. Lubow et al. 1975).

In support of the third proposition of their theory, Lubow et al. (1976b) report that latent inhibition effects can be attenuated if, during preexposure trials, a second novel stimulus follows the target stimulus. In the course of some recent work on second-order conditioning (Szakmary, Note 1), we incidentally obtained data which appear to corroborate this observation.

\section{EXPERIMENT 1}

Lubow et al. (1976b) presented two groups of rats with two stimuli $\left(S_{1}\right.$ and $\left.S_{2}\right)$ in either a paired or unpaired fashion. When $S_{1}$ alone was then paired with shock, the group for which $S_{1}$ had earlier preceded $S_{2}$ displayed greater suppression of licking (i.e., more conditioning). The first experiment replicates this finding within an Estes-Skinner conditioned emotional response paradigm.

Thanks are due to Drs. Leon J. Kamin and Jerry W. Rudy for their comments and suggestions regarding the manuscript. The author is now located at the Department of Psychology, Mather Memorial Building, Case Western Reserve University, Cleveland, Ohio 44106. Leon Kamin sponsors this paper and takes full editorial responsibility for its content.

\section{Method}

Subjects and apparatus. The subjects were 16 experimentally naive male albino rats (mean weight $=324 \mathrm{~g}$ ), obtained from Holtzman Company, Madison, Wisconsin. The rats were randomly divided into two groups of eight each and reduced to $75 \%$ of their ad-lib weight.

The apparatus consisted of eight standard operant conditioning units, individually housed in sound- and light-resistant chests. The two side walls and ceiling of each operant chamber were made of clear acrylic plastic, with a sheet of frosted translucent plastic covering each ceiling. The two end walls werc constructed of aluminum sheeting, with one end containing a bar, a food cup, and a loudspeaker. The floors of the chambers consisted of stainless steel grid rods connected to a GrasonStadler shock generator (E1064 GS). A $7.5-\mathrm{W}$ bulb was suspended over the ceiling of each chamber. The normal condition of the chambers was complete darkness.

The CS was a $30-\mathrm{sec} 80-\mathrm{dB}$ pulsating white noise $\left(\mathrm{S}_{1}\right)$ or a $10-\mathrm{sec}$ flashing $(1 / \mathrm{sec})$ of the overhead $7.5-\mathrm{W}$ light $\left(\mathrm{S}_{2}\right)$. The US was a $.5-\mathrm{sec}$ shock with a nominal intensity of $1.0 \mathrm{~mA}$. Programming and recording equipment was located in a room adjacent to the experimental room.

Procedure. Following initial magazine and barpress training, each rat received 10 daily 2 -h sessions of barpressing on a 2.5 -min variable-interval (VI) schedule of food reinforcement. During VI Days 4 and 5, the animals received a total of four pretest presentations each of the noise and light stimuli.

The daily 2-h barpressing sessions continued throughout the experiment. On each day of stimulus preexposure (VI Days 11 and 12), Group $S_{1}-S_{2}$ received four paired presentations of the $30-\mathrm{sec}$ white noise and the $10-\mathrm{sec}$ flashing light. Light onset coincided with offset of the noise stimulus. Group $S_{1} / S_{2}$ received the same number of daily noise and light stimuli, but these were spaced approximately $10 \mathrm{~min}$ apart (i.e., explicitly unpaired). Each group thus received a total of eight preexposed presentations of the target stimulus, the $30-\mathrm{sec}$ white noise CS. (There were also, it should be remembered, four pretest presentations of the same noise stimulus.)

Following the second preexposure day, all subjects were administered a single test session. The test consisted of four pairings of the 30 -sec noise and the $1-\mathrm{mA}$ shock, with shock onset coinciding with termination of the noise stimulus.

Throughout the experiment, responding to noise was assessed in terms of a suppression ratio. The ratio is of the form $B /(A+B)$, with $B$ representing the rate of barpressing during the $C S$ and $A$ the rate of barpressing in the 1 -min interval immediately preceding CS onset. The ratio has a value of .50 when the CS has no effect on ongoing operant responding and declines toward .00 as the CS, during the course of conditioning, comes to suppress barpressing completely. Suppression ratios were computed for each animal for each noise presentation during the experiment. 


\section{Results and Discussion}

There was no difference between groups in responding to noise during the pretest or preexposure trials, nor was there any difference on the first trial of the test (i.e., prior to the first reinforcing shock). Over the succeeding test trials, however, Group $S_{1}-S_{2}$ displayed greater suppression of barpressing than did Group $S_{1} / S_{2}$. The mean suppression ratio over Test Trials $2-4$ was .20 in Group $S_{1}-S_{2}, .31$ in Group $S_{1} / S_{2}$. The difference was significant $[\mathrm{t}(14)=2.34, \mathrm{p}<.05]$, thus confirming the findings of Lubow et al. (1976b).

It should be noted, however, that while the preexposure treatments did differentially affect the two groups, the data do not demand an interpretation in terms of latent inhibition effects. That is, in the absence of a "naive control," one need not conclude that $S_{1} / S_{2}$ subjects were retarded in the acquisition of conditioned suppression. Rather, the between-group differences may have been the result of a "savings" of conditioning among $S_{1}-S_{2}$ subjects. Such a savings might possibly arise from the noise-light pairings experienced by those subjects during stimulus preexposure trials. This possibility is not entirely unreasonable, since the 10 -sec flashing light stimulus was observed to produce substantial unconditioned suppression of barpressing during the preexposure trials. The data of Experiment 2, also gathered during investigations of second-order conditioning, permit a test for such a "savings" effect.

\section{EXPERIMENT 2}

\section{Method}

Subjects and apparatus. The subjects were 16 experimentally naive male albino rats (mean weight $=339 \mathrm{~g}$ ), obtained from Holtzman Company. The rats were divided into groups of eight and maintained as in Experiment 1. The apparatus was the same as that of the previous experiment. The CS was a 30-sec 80-dB pulsating white noise $\left(S_{1}\right)$ or a 10-sec flashing of the overhead $7.5-\mathrm{W}$ light $\left(\mathrm{S}_{2}\right)$. The US was a $1.0-\mathrm{mA}$ shock with a duration of $.5 \mathrm{sec}$.

Procedure. Except for providing a new experimental treatment, a no-treatment (NT) control, the procedure was identical to that employed in Experiment 1 . The rats were barpress trained and administered four pretest presentations each of the 30 -sec noise and 10 -sec light. Following 10 days of VI barpressing, Group $S_{1}-S_{2}$ received 2 days of preexposure (four trials per day) to the noise stimulus. Each presentation of the noise was immediately followed by the 10 -sec light. During the preexposure days, Group NT received no stimulus presentations, but continued the 2-h barpressing sessions. Testing was then carried out as in Experiment 1. All animals received four pairings of the $30-\mathrm{sec}$ noise and $1.0-\mathrm{mA}$ shock. Suppression ratios were. again used to assess responding to the noise stimulus.

\section{Results and Discussion}

There was no difference between groups in responding to noise during the pretest or on the first test trial. Over the succeeding test trials (Trials 2-4), the mean ratio was .24 for Group $S_{1}-S_{2}, .17$ for Group NT. Though these data suggest that NT may have displayed greater suppression to noise than did Group $S_{1}-S_{2}$, this difference was not significant $[t(14)<1]$.
The data do make clear that pairing noise with light during preexposure trials does not produce a "savings" of noise conditioning in the test. The difference observed in Experiment 1 between Groups $S_{1}-S_{2}$ and $S_{1} / S_{2}$ might, therefore, be attributed to latent inhibition effects in the latter treatment. One may wish to conclude further that the environmental change (i.e., $S_{2}$ ) which was presented consequent to each noise preexposure in Group $S_{1}-S_{2}$ served to reduce the latent inhibition of noise in that group. The collective data of Experiments 1 and 2 are at least consistent with such an interpretation, and confirm the prior work of Lubow et al. (1976b).

The pairing of $S_{1}$ with $S_{2}$ during preexposure trials has now been found to attenuate latent inhibition effects under a variety of circumstances (cf. Lubow et al., 1976b). Such attenuation has been obtained with differing response systems, a variety of stimulus modalities and durations, and a wide range (8-120) of preexposure trials. Furthermore, Wagner (in press), employing a vasomotor response with rabbits, has found habituation of $S_{1}$ to be retarded when that stimulus is followed by an $S_{2}$.

These observations, it should be noted, do not necessarily warrant an interpretation in terms of conditioned attention theory, as Lubow et al. (1976b), p. 168) acknowledge. At least two alternative accounts of the data are possible. First, Wagner (in press) has argued that the response initially produced by a novel stimulus diminishes as that stimulus comes to be signaled by the situational or contextual cues within which it is presented. According to this view, $S_{2}$ serves to distract the subject, thus interfering with the storage of information regarding the context- $S_{1}$ relationship. This, in turn, retards the development of response decrements to $S_{1}$. Thus, while Lubow et al. (1976b) see $S_{2}$ as maintaining attention to $S_{1}$, Wagner (in press) argues that $S_{2}$ weakens the memorial representation of $S_{1}$.

Alternatively, the advantage of Group $S_{1}-S_{2}$ over Group $S_{1} / S_{2}$ in the conditioning test might be the result of differential stimulus change in the test, rather than of differences in the degree of latent inhibition developed during preexposure trials. For example, precisely when the reinforcing shock in the test occurs, $S_{1}-S_{2}$ subjects are also experiencing the absence of $S_{2}$ following $S_{1}$. This change in stimulation (from $S_{1}-S_{2}$ pairings in preexposure trials) may act to offset "latent inhibition" previously established to $S_{1}$. This, in turn, could reinstate the "normal" rate of conditioning for that stimulus. Evidence in fact exists that such a change in stimulation can attenuate latent inhibition effects (Lubow, Rifkin, \& Alek, 1976a), as well as, more generally, enhance conditioning (Gray \& Appignanesi, 1973). In view of its implications for the response decrement theories of Lubow and Wagner, this last possibility would appear to be well worth testing.

Such a test could be conducted in a relatively straightforward manner. Two groups of subjects could 
be provided with the $S_{1}-S_{2}$ preexposure treatment. Then, during the test, both groups would receive $S_{1}$ shock pairings. However, for one of the groups $S_{2}$ would continue to follow each test presentation of $\mathrm{S}_{1}$-and, thus, be simultaneous with the delivery of shock. If the change in stimulation (i.e., absence of $S_{2}$ ) in the test serves to enhance conditioning of $S_{1}$, the group receiving $S_{1}$-shock pairings without presentation of $S_{2}$ would be expected to display more rapid conditioning. This possibility is currently being examined in our laboratory.

\section{REFERENCE NOTE}

1. Szakmary, G. A. Second-order conditioning of the conditioned emotional response. Unpublished doctoral dissertation, Princeton University, 1976.

\section{REFERENCES}

Gray, T., \& Appignanesi. Compound conditioning:
Elimination of the blocking effect. Learning and Motivation. 1973, 4, 374-380.

Lubow, R. E., Alek, M., \& ARzy, J. Behavioral decrement following stimulus pre-exposure: Effects of number of preexposures, presence of a second stimulus, and interstimulus interval in children and adults. Journal of Experimental Psychology: Animal Behavior Processes, 1975, 1, 178-188.

Lubow, R. E., Rifkin, B., \& Alek, M. The context effect: The relationship between stimulus pre-exposure and environmental pre-exposure determines subsequent learning. Journal of Experimental Psychology: Animal Behavior Processes, 1976, 2. 38-47. (a)

Lubow, R. E., SchnuR, P., \& Rifkin, B. Latent inhibition and conditioned attention theory. Journal of Experimental Psychology: Animal Behavior Processes, 1976, 2, 163-174. (b)

W AGNer, A. R. Priming in STM: An information processing mechanism for self-generated or retrieval-generated depression in performance. In T. S. Tighe \& R. N. Leaton (Eds.), Habituation: Perspectives from child development. animal behavior, and neuro-physiology. Hillsdale, N.J: Lawrence Erlbaum. in press.

(Received for publication October 1, 1976.) 